\title{
Influence of strain rate on the mechanical response of nanostructured coppers elaborated by SPD and SPS
}

\author{
Hervé Couque ${ }^{*}$, Yuri Khoptiar ${ }^{2}$, Frédéric Bernard ${ }^{3}$, Itamar Gutman ${ }^{2}$, Florian Bussiere ${ }^{3}$, Foad Naimi $^{4}$, Rémi \\ Boulanger ${ }^{1}$ and François Barthélémy ${ }^{5}$ \\ ${ }^{1}$ Nexter Munitions, Bourges, France \\ ${ }^{2}$ Rafael, Haifa, Israël \\ ${ }^{3}$ ICB - UMR 6303 CNRS / UBFC, Dijon, France \\ ${ }^{4}$ Sintermat, Montbard, France \\ ${ }^{5}$ DGA Tt, Bourges, France
}

\begin{abstract}
The influence of strain rate on the mechanical response of two different nanostructured pure coppers was investigated under uniaxial compression. The first nanostructured copper was elaborated by powder metallurgy using the Spark Plasma Sintering (SPS) process. The second nanostructured copper was elaborated by Severe Plastic Deformation (SPD). Conventional characterizations were conducted with quasi-static compression and tensile tests, hardness tests and, with microstructure analysis. The effect of strain rate was evaluated under uniaxial compression at strain rates varying from $10^{-4}$ to $10^{+4} \mathrm{~s}^{-1}$. The high strain rate data were generated with a direct Hopkinson impact technique. The increase of strength with strain rates was analysed and discussed from the Scanning Electron Microscope observations and grain size distribution. The mechanical properties are consequently dependent on the metallurgical history of these samples prepared according to two different routes.
\end{abstract}

\section{Introduction}

Many examples in the literature illustrate the specific characteristics of nanophased materials in electronics, magnetic recording, cosmetics, catalysis, etc. [1-6]. However, it is very difficult to access to the evolution of mechanical properties versus the grain size. The difficulty to evaluate mechanical properties of nanomaterials has been attributed to the difficulty in preparing significant size dense specimens [7]. Nevertheless, some examples showed clearly that the improvement of mechanical properties of metals and alloys is historically related to a refinement of microstructure, since with a decreasing of the grain size the yield strength increases according to the Hall-Petch law [8-10]. The development of substructure limits the dislocation motions via the precipitation - creation of dislocation cells (10-200 nm) and, consequently, reinforces the compromise between yield stress and ductility [11].

The present work examines two processing ways capable to generate nanostructured copper having different microstructures. The first route involves materials elaborated by a sintering from nanostructured powders. Nanostructured powders were generated using high-energy ball milling. Such technique permits to generate micrometric agglomerates composed of nanostructured powders facilitating their storage, transport, and handling. Moreover, the combination of mechanical and electrical activations techniques involving fast heating rates has been recognized to be a suitable solution to produce dense nanostructured materials. Such approach has been optimized through the Spark Plasma Sintering (SPS) technique allowing the elaboration of dense metallic parts having a fine microstructure [12]. The second route involves nanomaterials elaborated by the Severe Plastic Deformation process (SPD) starting from conventional copper bars [13]. The bars were deformed with the Equal Channel Angular Pressing technique (ECAP).

The influence of strain rate on the mechanical response of the two different nanostructured pure coppers was investigated under uniaxial compression, with strain varying from $10^{-4} \mathrm{~s}^{-1}$ to $10^{4} \mathrm{~s}^{-1}$. A microstructure analysis was performed in order to analyse such results.

* Corresponding author: h.couque@nexter-group.fr 


\section{Experimental procedure}

\subsection{Material processing and microstructural analysis procedures}

\section{Spark Plasma Sintering approach}

A $99.6 \%$ pure copper powder with a narrow particle size distribution (i.e., D10: $18.4 \mu \mathrm{m}$, D50: $27.5 \mu \mathrm{m}$ and D90: $42.7 \mu \mathrm{m}$ ) made by the Tekna Company was used. This powder was prepared using Inductively Coupled Plasma method, which has the advantage to produce pure spherical particles without any oxide either on the surface or inside the particle. The oxygen content was low $(0.041 \mathrm{wt} . \%)$. That is why an oxide of few nanometer thickness only covers the particle surface. Consequently, $\mathrm{Cu}$ powders were received in vacuum containers and placed in a glove box This procedure makes it possible to avoid any re-oxidation of the powder as in the case for two types of powders, identified as CuSPS1 and CuSPS2 powders. However, it was decided to study the influence of the oxygen contamination on the tensile properties using powders which present more oxides because they have been prepared outside the glove box, identified CuSPS3 powders.

In order to generate nanostructured agglomerates, the milled powders were prepared using Fritsch pulverisette 4 planetary ball mill, see Fig. 1. With this type of planetary mill, two rotations expressed in rotation per minute $(\mathrm{rpm})$ can be modified independently: a rotation of the plate $(\Omega)$ on which are fixed the bowls and a rotation in the opposite direction of the bowls $(\omega)[14,15]$. Depending on the selected rotation speeds, it is possible either to promote collisions or frictions (i.e. energy and frequency of shocks). Moreover, the vials are filled inside a glove box maintained under argon atmosphere in order to avoid oxidation. The copper powders were ground according to the condition $\Omega /-\omega / \mathrm{h}=250 \mathrm{rpm} /-50 \mathrm{rpm} / 8 \mathrm{~h}$. The size distribution of mechanically activated agglomerates ranges from 50 to $300 \mu \mathrm{m}$ after milling.

Then, these powders were sintered in vacuum using a Spark Plasma Sintering technique, see Fig. 2 [12]. Such a fast-heating process permits to limit the grain growth, therefore generating a dense nanostructured copper. As copper is a conductive material, the current go through the sample and, consequently, this latter is heated by its own Joule effect. Sintered samples of $60 \mathrm{~mm}$ in diameter and $10 \mathrm{~mm}$ in height were obtained. The displacement of the punches was continuously recorded during the SPS experiments to evaluate the sample shrinkage.

$\mathbf{6}$

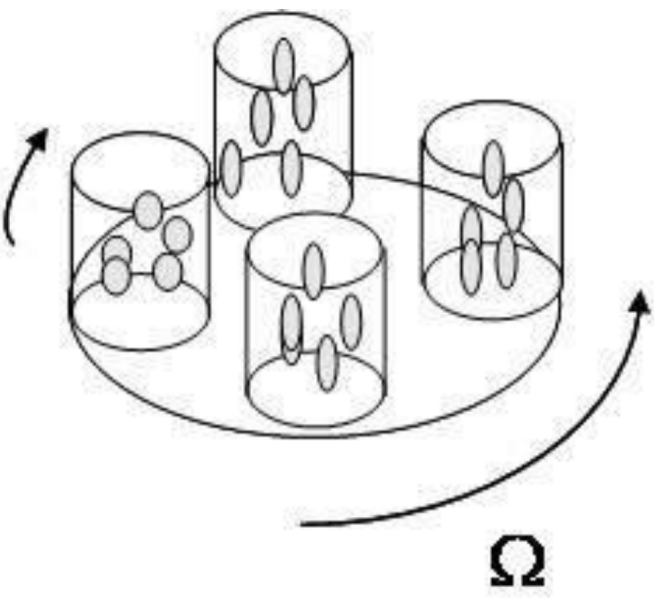

Fig. 1. Schematic illustration of the high-energy ball milling process.

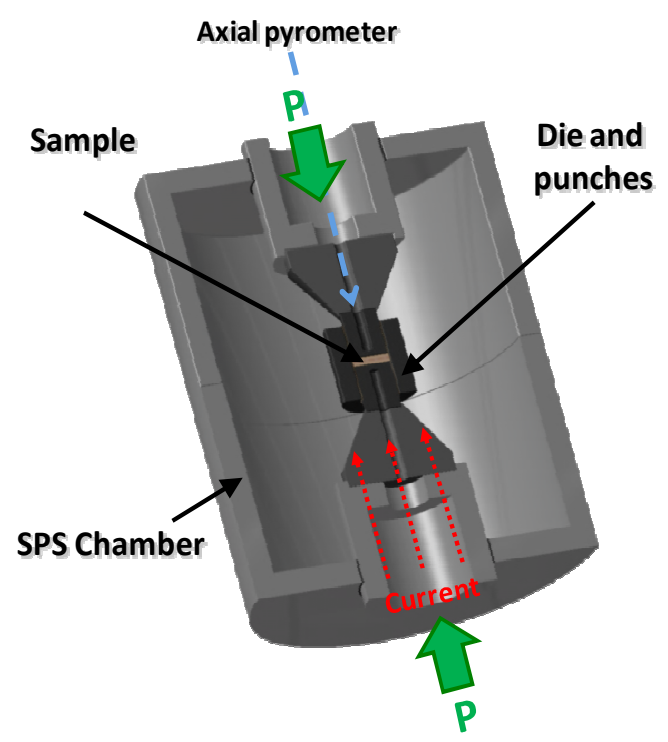

Fig. 2. Spark Plasma Sintering Technique [12]. 
Severe plastic deformation approach

The copper used in this part is conform to ASTM B187, with a high purity $(99,99 \%)$ and a grain size close to $35 \mu \mathrm{m}$. The severe plastic deformation process uses an Equal Channel Angular Pressing technique (ECAP), see Fig. 3 [13].

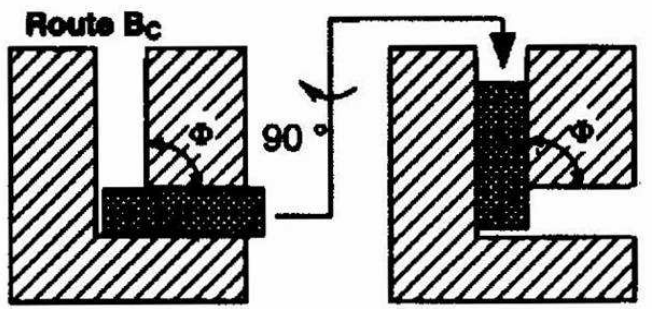

Fig. 3. Equal Channel Angular Pressing Technique [13].

The approach consists in passing several times a bar of the raw material in an angular die $50 \mathrm{~mm}$ in diameter to break down the microstructure. The process has been repeated four times as to generate a nanostructured copper. Then, after the severe plastic deformation treatment, it was decided to find the optimal conditions to achieve stress relaxation and the recrystallization stage. Thus, from Fig. 4, it was possible to prepare three samples presenting different microstructures: CuSPD1, ECAP and a heat treatment at $130^{\circ} \mathrm{C}$ to relax the stresses, CuSPD2 ECAP followed by a heat treatment at $150^{\circ} \mathrm{C}$ leading to a partially recrystallized sample and CuSPD3 ECAP plus a heat treatment at $200^{\circ} \mathrm{C}$ for obtaining a specimen totally recrystallized.

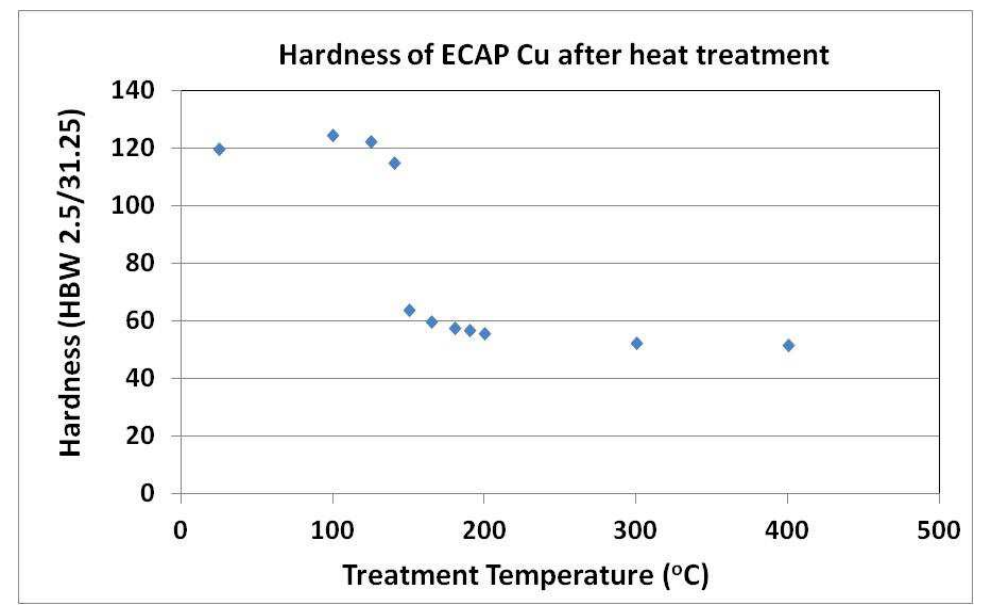

Fig. 4. Evolution of the hardness versus the thermal treatment applied on ECAP samples.

\subsection{Mechanical characterisation procedures}

To evaluate mechanical properties, hardness and tensile tests were carried out. The Hardness Vickers (HV), was measured at ten spots for each sintered sample with $10 \mathrm{~kg}$ load for $10 \mathrm{sec}$ (HV10). Three cylinders were extracted from each sample by Electrical Discharge Machining (EDM), from which tensile specimens were machined with a gage section of $16 \mathrm{~mm}$ in width and $4 \mathrm{~mm}$ in diameter. Uniaxial tensile tests were performed at a constant strain rate of $10^{-3} \mathrm{~s}^{-1}$ using a conventional testing machine type TESTWELL. The load was measured with a $100 \mathrm{kN}$ load cell and the displacement was measured with a clip gage over a $10 \mathrm{~mm}$ gage length.

Compression tests were conducted with specimens of $9 \mathrm{~mm}$ in diameter $5 \mathrm{~mm}$ in height. Quasi-static compression tests were conducted at $10^{-4} \mathrm{~s}^{-1}$ with a conventional testing machine. A Direct Impact Hopkinson Pressure Bar (DIHPB) technique compression apparatus was used to generate compression data in the $10^{3}$ to $10^{4} \mathrm{~s}^{-1}$ strain rate regimes. The DIHPB, introduced by Dharan \& Hauser [16] and revisited by Klepaczko and by Couque [17,18], consists in impacting at a constant velocity with an impactor a specimen placed against a Hopkinson pressure bar, as shown in Fig. 5. The impactor speed, $V_{i}$, typically between 30 and $150 \mathrm{~m} . \mathrm{s}^{-1}$, is recorded just prior impact with the help of laser beam device. A strain gage is placed on the Hopkinson bars in order to provide the loading history of the specimen. 


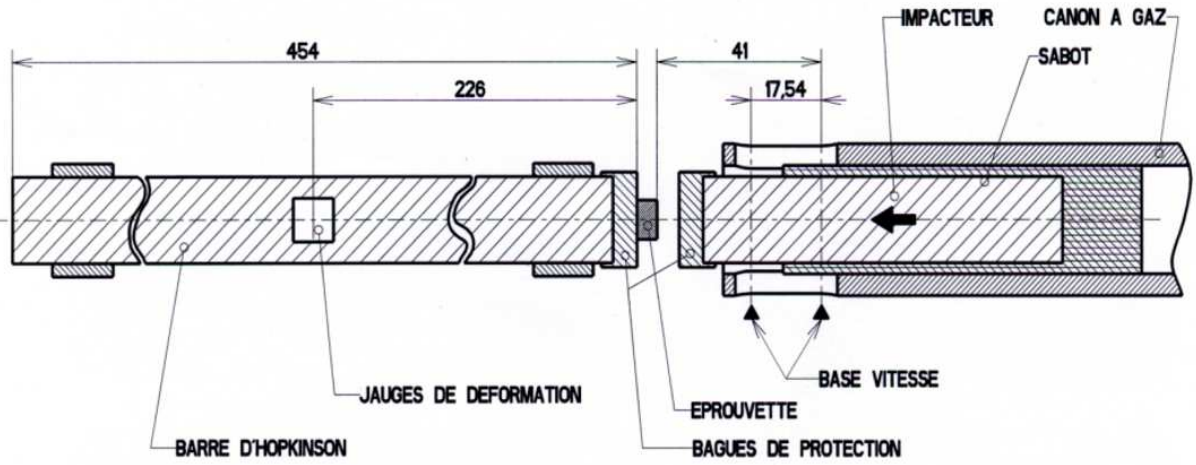

Fig. 5. Direct Impact Hopkinson Pressure Bar technique (DIHPB).

The impact velocity is assumed to be constant during the tests. This hypothesis holds when the impactor mass is large enough as to provide a kinetic energy greater than the plastic deformation of the specimen. With such a hypothesis, the true axial strain, true axial stress and associated strain rate are deduced following the procedure described in [18].

Microstructural analysis procedure

The apparent density of samples is determined using a helium pycnometer. X-Ray Diffraction (XRD) analyses were performed with a Bruker-AXS D8 Advance diffractometer $(\mathrm{CuK} \alpha$ radiation, $\lambda=0.154051 \mathrm{~nm})$. Cell parameter, crystallites size and microdistorsion rate were evaluated by a decomposition method of XRD patterns using the Pawley - Le Bail method [19]. The global chemical analysis is performed by XRF spectrometer type Bruker. The microstructure observations of the dense materials are carried out using a Scanning Electron Microscope (SEM), type JEOL JSM-7600F, with a Field Emission Gun (FEG).

\section{Results and Discussion}

\subsection{Mechanical characterisation data}

Results of mechanical tests (tensile and hardness) are summarized in Table 1. This Table 1 and Fig. 6 show clearly that the mechanical properties are dependent on the microstructure (i.e. metallurgical history) induced during both SPS and SPD processes. It can be noted that the two fundamentally different processes, SPS and SPD, lead to coppers with similar yield strength-ductility dependence.

The higher yield strength seems to be obtained for the sample CuSPD1 which gets a low ductility whereas the best compromise is obtained for the sample CuSPS2 sintered from mechanical activated powders in which a distribution between micrometric grains and submicronic grains is induced. With the CuSPD1 and CuSPS2 samples taken as references for each preparation route, the presence of oxides with the CuSPS3, presenting the same bi-structure as the reference, reduces the ductility, while the presence of zones containing some recrystallized grains with the CuSPD2 and CuSPD3 reduces the strength.

Table 1. Mechanical properties obtained on SPD and SPS samples composed of different microstructures.

\begin{tabular}{|c|c|c|c|c|}
\hline \multicolumn{5}{|c|}{ Severe Plastic Deformation } \\
\hline Material & Temperature heat treatment $\left({ }^{\circ} \mathrm{C}\right)$ & $\sigma_{\mathrm{y}}(\mathrm{MPa})$ & $\varepsilon(\%)$ & $\mathrm{HV}_{10}$ \\
\hline CuSPD1 & Heat treated $130^{\circ} \mathrm{C}$ & 375 & 15.7 & 120 \\
\hline CuSPD2 & Heat treated $150^{\circ} \mathrm{C}$ & 125 & 40.5 & 65 \\
\hline CuSPD3 & Heat treated $200^{\circ} \mathrm{C}$ & 90 & 43.8 & 57 \\
\hline \multicolumn{5}{|c|}{ Spark Plasma Sintering } \\
\hline Material & SPS conditions & $\sigma_{\mathrm{y}}(\mathrm{MPa})$ & $\varepsilon(\%)$ & $\mathrm{HV}_{10}$ \\
\hline CuSPS1 & Unmilled, $800^{\circ} \mathrm{C} / 50 \mathrm{MPa} / 10 \mathrm{~min}$ & 88 & 46.0 & 50 \\
\hline CuSPS2 & Milled, $650^{\circ} \mathrm{C} / 70 \mathrm{MPa} / 10 \mathrm{~min}$ & 204 & 34.4 & 81 \\
\hline CuSPS3 & $\begin{array}{l}\text { Milled, degassing stage } 30 \mathrm{~min} \text { at } 450^{\circ} \mathrm{C} \text { and } \\
650^{\circ} \mathrm{C} / 70 \mathrm{MPa} / 10 \mathrm{~min}\end{array}$ & 238 & 14.0 & 94 \\
\hline
\end{tabular}




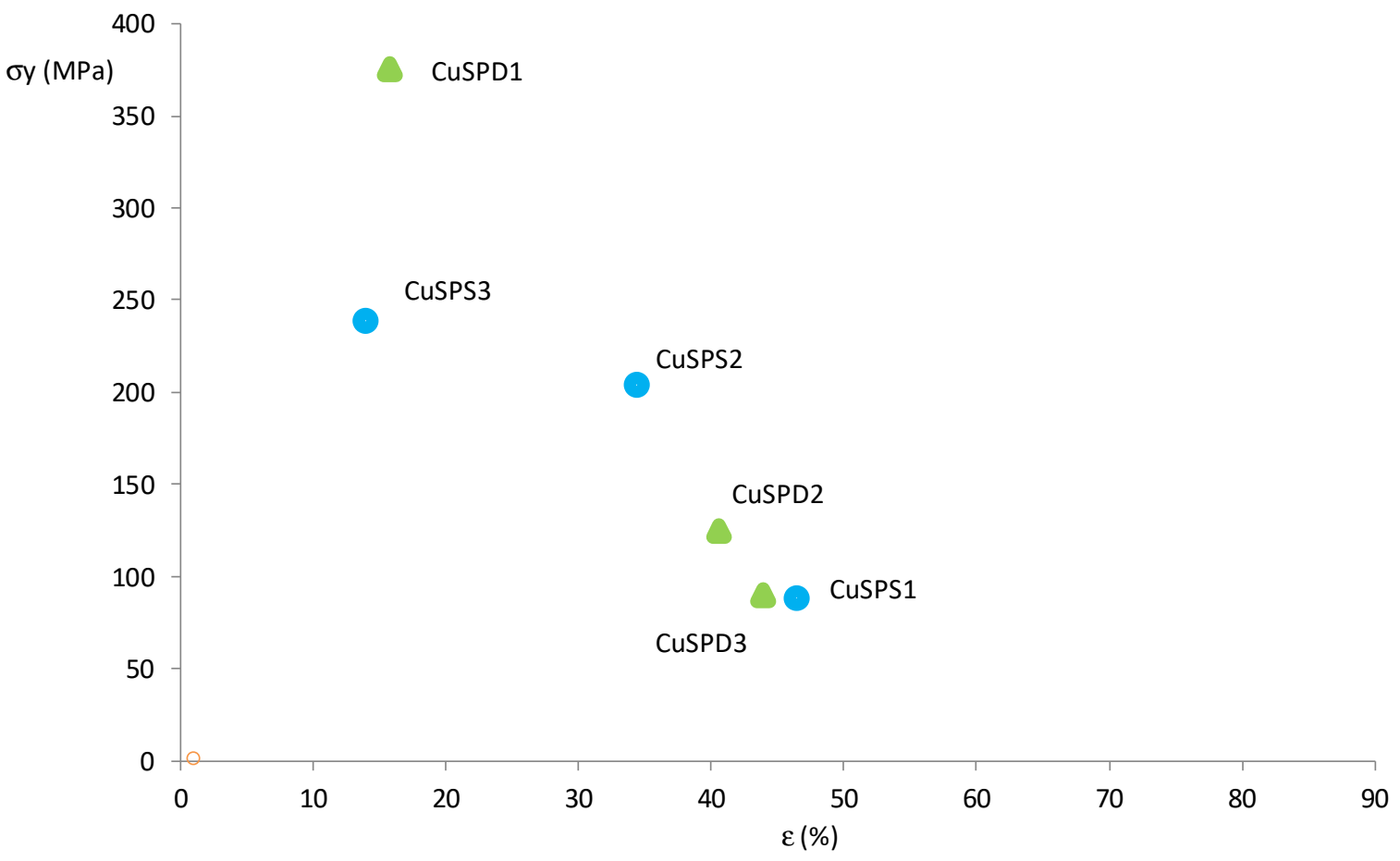

Fig. 6. Tensile true yield stress versus true strain.

As expected, in the case of SPS process, the mechanical activation stage is an effective method for decreasing the sintering temperature. Indeed, the sintering temperature decreases from $800^{\circ} \mathrm{C}$ to $650^{\circ} \mathrm{C}$ for unmilled powders to milled powders, respectively. The decrease of the sintering temperature is attributed to the ball milling implying the reduction of the crystallite size and to the multiplication of structural defects leading to an increase of microdistorsions. During the ball milling process, micrometric copper powder undergoes very large deformation due to successive fracture and welding processes. This causes a significant change in the morphology of particles by a generation of large micrometric agglomerates from 20 to $300 \mu \mathrm{m}$ composed of nanocrystallites and by a multiplication of structural defects such as stacking faults, twins, dislocations [20].

Concerning the SPD process, the necessity to apply a heat treatment on ECAP sample, in particular, to increase the ductility is confirmed. Unfortunately, the recrystallisation process is responsible to the decreasing of the yield strength. Nevertheless, it seems possible, from this preparation route (i.e. ECAP followed of a recrystallisation stage) to manage the couple yield stress / ductility by a better control of the quantity of the recrystallized grains.

\subsection{Microstructural analysis procedures data}

In order to analyze the mechanical behavior between SPD and SPS samples, several microstructure characterizations were performed in terms of chemical composition and crystallographic data, see Table 2.

Table 2. Chemical composition (XRF) and phase analysis (XRD)

\begin{tabular}{|l|l|l|l|l|}
\hline Samples & $\begin{array}{l}\text { Cell parameter } \\
(\mathrm{A})\end{array}$ & $\begin{array}{l}\text { Crystallite size }(\mathrm{nm}) / \\
\text { microstrain rate }\end{array}$ & $\begin{array}{l}\text { Volume mass } \\
\left(\mathrm{g} / \mathrm{cm}^{3}\right)\end{array}$ & Global chemical analysis \\
\hline CuSPS1 & 3.6175 & $>250 / \mathrm{n}$. a. & 8.78 & $99.57(\mathrm{Sn})$ \\
\hline CuSPS2 & 3.6179 & $72 / 11 \%$ & 8.81 & $99.55(\mathrm{Sn}, \mathrm{Fe})$ \\
\hline CuSPS3 & 3.6174 & $100 / 21 \%$ & 8.65 & $99.33(\mathrm{Sn}, \mathrm{Si}, \mathrm{Fe})$ \\
\hline CuSPD1 & 3.6173 & $55 / 10 \%$ & 8.74 & $99.65(\mathrm{Si})$ \\
\hline CuSPD2 & 3.6178 & $88 / 1 \%$ & 8.74 & $99.73(\mathrm{Ni})$ \\
\hline CuSPD3 & 3.6178 & $98 / 7 \%$ & 8.78 & $99.30(\mathrm{Fe})$ \\
\hline
\end{tabular}

Moreover, SEM observations were performed on SPS samples, see Fig. 7. Fig 7a shows that the sample CuSPS2 is dense and it is composed of a grain size distribution (i.e. mixture between micrometric grains, $10 \mu \mathrm{m}$ and submicrometric grains, $<1 \mu \mathrm{m}$ ). 

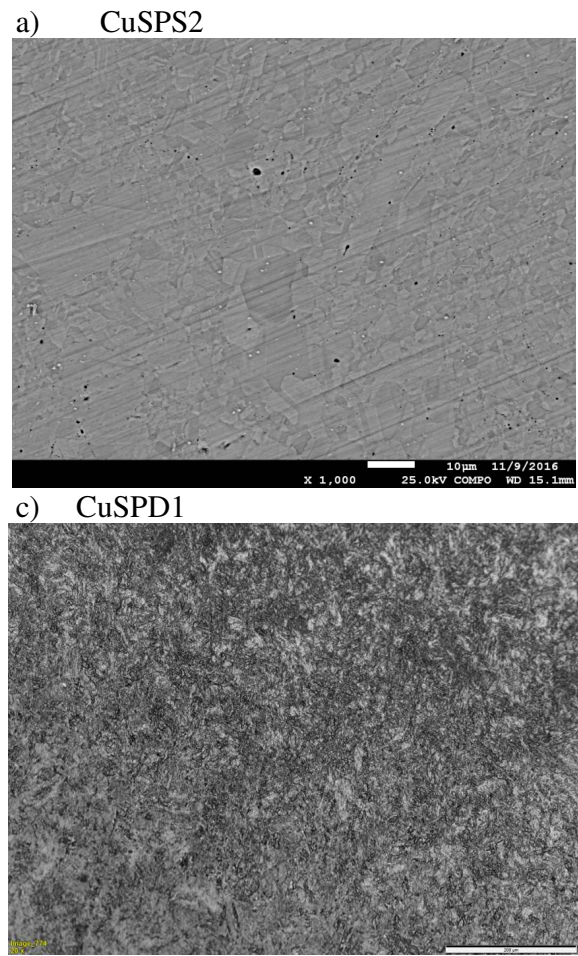

b) CuSPS3 with oxides
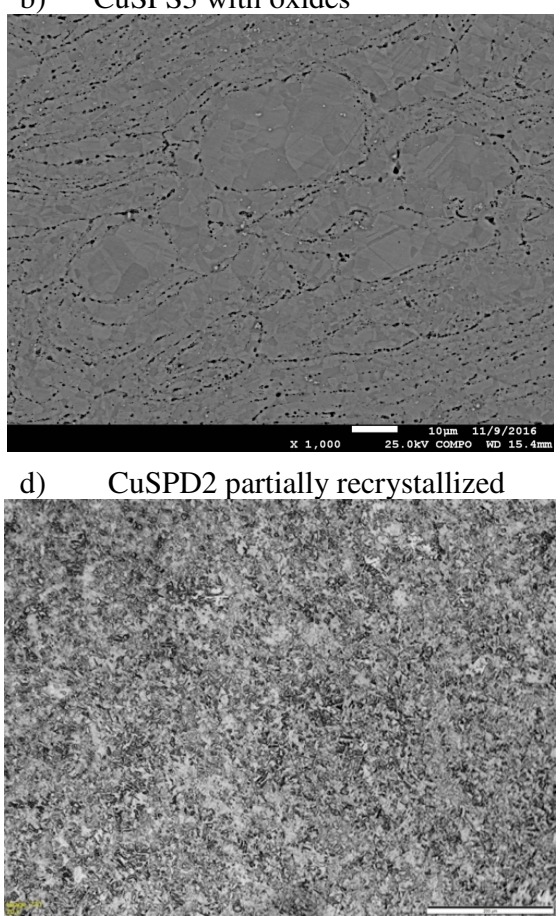

Fig. 7: SEM observations of the SPS materials (a and b) and optical microscopy observations of SPD materials (c and d).

This distribution can explain the good balance between moderate yield strength (204 MPa) and good ductility $(34.4 \%)$. On the contrary, the presence of oxides, black dots on the Fig. 7b, on sample CuSPS3 modified the mechanical properties specially in terms of ductility. This observation confirms that it is essential to limit as often as possible the presence of oxygen all along the preparation.

Concerning the ECAP samples, the microstructure of CuSPD1 presented Fig. 7c seems homogeneous in terms of grain size. The high level of the yield strength $(375 \mathrm{MPa})$ is certainly due to the presence of stresses induced during ECAP combined to the generation of a fine microstructure but, its ductility stays relatively low (14.4\%). However, as expected, a heat-treatment at $150^{\circ} \mathrm{C}(\mathrm{CuSPD} 2)$ leading to the initiation of the recrystallisation process is efficient to decrease the level stress stored in the ECAP sample (125 MPa) and to lead to the formation of new grains without defects.

\subsection{Strain rate influence on mechanical response}

All results obtained from Hopkinson experiments are presented on the Fig. 8a. This figure compares, for a dependence at a true strain 0.05, the behaviour of: (i) two samples prepared by SPS, CuSPS2 bi-structure (10 $\mu \mathrm{m}$ and $1 \mu \mathrm{m})$ without oxides and CuSPS3 bi-structure $(10 \mu \mathrm{m}$ and $1 \mu \mathrm{m})$ with oxides and (ii) two samples produced by ECAP, CuSPD1 non-recrystallized $(1 \mu \mathrm{m})$ and CuSPD2 partially recrystallized with bi-structure composed of recrystallized grains of $20 \mu \mathrm{m}$ and non-recrystallized grains (1 to $5 \mu \mathrm{m})$.

In addition, the influence of the strain rate versus the mechanical response is detailed on Fig. 8b, $8 \mathrm{c}, 8 \mathrm{~d}$ and $8 \mathrm{e}$. The Fig. 8a shows that the influence of the strain rate on the mechanical response of the CuSPD1 sample is negligible in comparison with others. The behaviour may be attributed a microstructure composed of numerous defects. Most likely, the microstructure presents a saturated density of dislocations, inducing a yield stress independent on temperature and strain rate.

The dependence on the strain rate of SPS products (CuSPS2 and CuSPS3 containing oxides) may be due to the presence of two populations of agglomerates. Indeed, the Fig. 7a relating to the CuSPS2 sample shows that a size distribution exists between micrometric size grains $(10 \mu \mathrm{m})$ and those with a submicrometric size $(<1 \mu \mathrm{m})$. This distribution has been already observed in the case of the preparation of dense nickel sintered by SPS from mechanically activated agglomerate powders [21]. Thus, by modifying the milling conditions, it seems possible to modulate the tensile properties by a modulation of the grain size repartition. 
Moreover, this trend is confirmed on the sample prepared by SPD followed by a heat treatment at $150^{\circ} \mathrm{C}$ (i.e. partially recrystallized sample) which is also characterized by a bi-structure composed of the original grains issued from ECAP $(1-5 \mu \mathrm{m})$ and recrystallized grains $(20 \mu \mathrm{m})$.

The bi-structure of the SPS samples and partially recrystallized SPD sample reveals a similar strain rate dependence, either in the thermally activated regime or in the viscous regime. It appears that the small grains of the bi-structures control the transition from the thermally activated regime to the viscous regime. Precisely, the yield strength increases with the decrease of the grain size, both for SPS and SPD samples.

a)

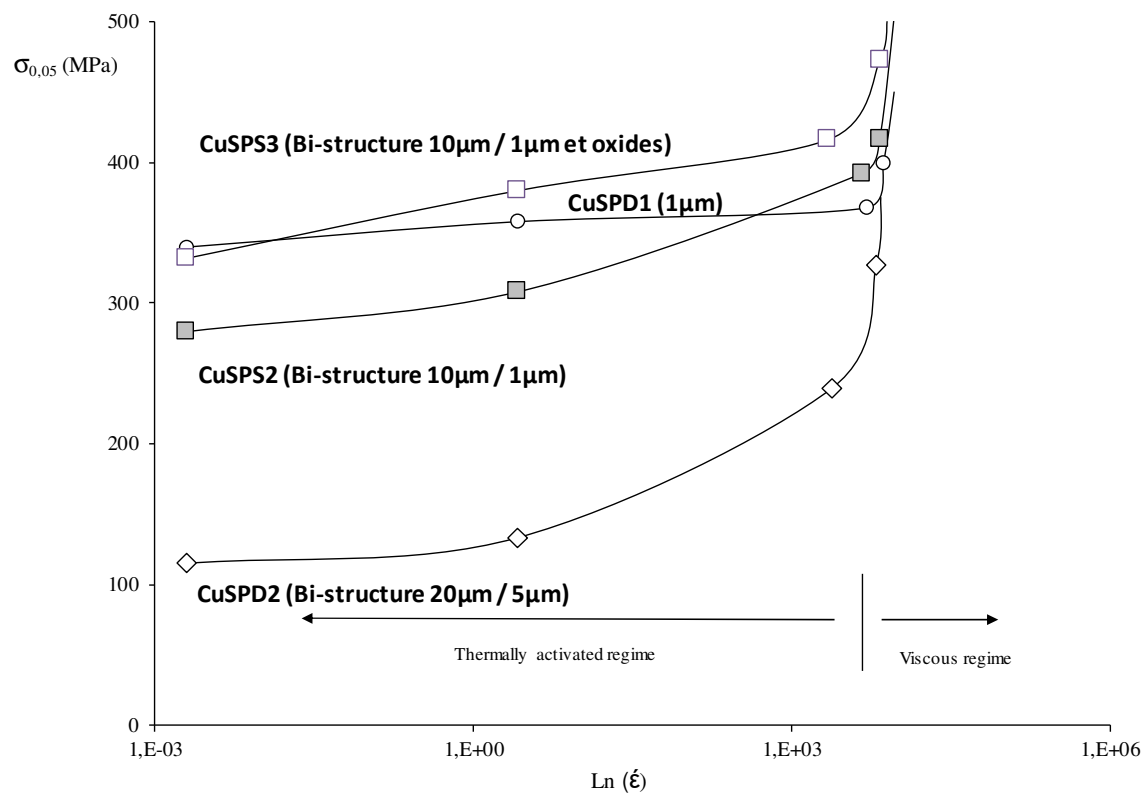

b) $\quad I \sigma I(\mathrm{MPa})$

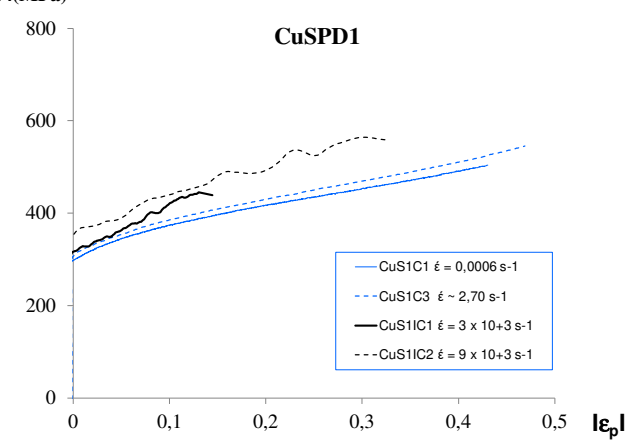

d) $\quad I \sigma_{c} l(M P a)$

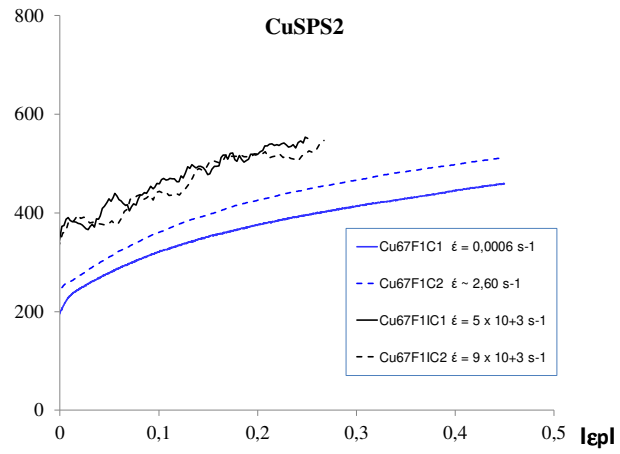

c) $\quad|\sigma|(\mathrm{MPa})$

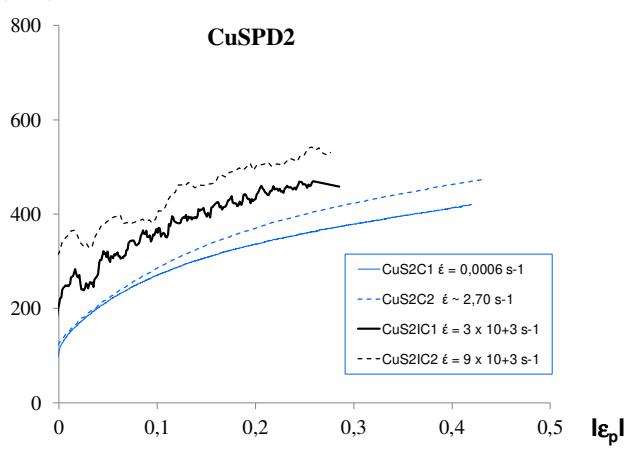

e) $\quad\left|\sigma_{c}\right|(M P a)$

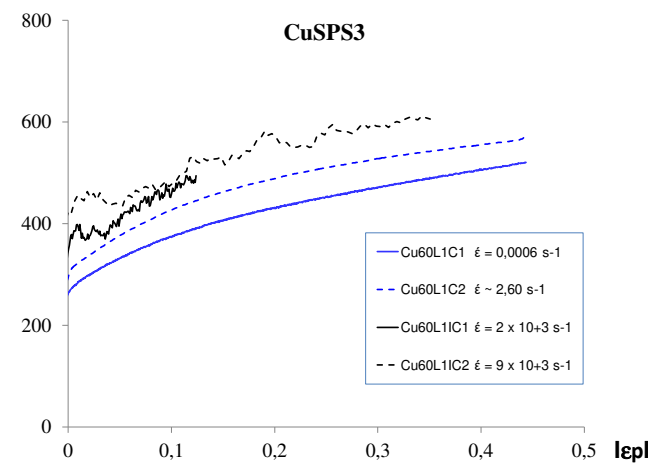

Fig. 8. Responses at function of strain rate a) at a strain of $0,05, b$ ) and c) true strain true strain curves for SPD materials, d) and e) for SPS materials. 


\section{Conclusion}

The relationship between the microstructure of materials prepared by SPS and SPD routes and the mechanical properties under quasi-static or in dynamic loading conditions was investigated. For both routes, SPS and SPD, some cautions are necessary for controlling the microstructure in terms of size distribution and the stress rates (i.e. presence of structural defects). The best yield strength (375 MPa) is obtained in the case of CuSPD1 but the ductility of $14.6 \%$ is not sufficient for the shaping of this material. Consequently, a heat-treatment such as a recrystallisation stage is essential to increase its ductility. Unfortunately, the yield strength decreases drastically showing that it is essential to control the part of recrystallized grains as it can be observed in the case of the sample CuSPD2 which has been partially crystallized at $150^{\circ} \mathrm{C}$ (i.e. yield strength of $125 \mathrm{MPa}$ and $40 \%$ of ductility).

Concerning samples prepared by SPS sintering of mechanically activated powders, a promising compromise was obtained between yield strength (204 MPa) and ductility (34.4\%). This latter may be attributed to a specific microstructure composed of two population of grains. This bimodal distribution is directly due to the high energy milling which led to a large distribution of nanostructured agglomerates. The main difficulty encountered during this preparation way is the necessity to limit the oxygen contamination along each step. It is advised to limit the contact between $\mathrm{Cu}$ powders and atmosphere. Thus, it was decided to work in glove box in which oxygen level and hygrometric rate were controlled.

In conclusion, in both cases, it seems essential to control the bimodal distribution of grains to control the couple yield strength and ductility.

\section{Acknowledgments}

The authors thank MM. P. Vanneau et S. Tisserand for conducting the compression tests. This research was in part sponsored by the Israël MOD and the French MOD. 


\section{References}

1. M. Lahmani, C. Bréchignac, and P. Houdy, Nanomaterials and Nanochemistry, Springer, Berlin, Germany (2007)

2. G. Schmid, "Nanoclusters: Building blocks for future nanoelectronics Devices," Advanced Engineering Materials, 3, 737 (2001)

3. C. Pirlot, "Preparation and characterization of carbon nanotube/polyacrylonitrile composites," Advanced Engineering Materials, 4, 109 (2002)

4. C. Edser, "Nanopowders seek commercial roles to repay R\&D effort," Metal Powder Report, 54, 4, 11 (1999)

5. J.M. Capus, "Prospects look promising for nanopowders," Metal Powder Report, 56, 1, 12 (2001)

6. B. H. Kear and G. Skandan, "Overview: status and current developments in nanomaterials," International Journal of Powder Metallurgy, 35, 7, 37 (1999)

7. H.Hahn and K. A. Padmanabhan, "Amodel for the deformation of nanocrystalline materials," Philosophical Magazine B, 76, 4, 559 (1997)

8. E. O. Hall, "The deformation and ageing of mild steel: III Discussion of results," Proceedings of the Physical Society B, 64, 9, 303, 747 (1951)

9. N. J. Petch, "Cleavage strength of polycrystals," Journal of Iron and Steel Institute, 174, 25 (1953)

10. H. Gleiter, "Nanocrystalline materials," Progress in Materials Science, 33, 4, 223 (1989)

11. S. Zaefferer, "Investigation of the correlation between texture and microstructure on a submicrometer scale in the TEM," Advanced Engineering Materials, 5, 8, 607 (2003)

12. R. Orrù, R. Licheri, A. Locci, A.Cincotti, G. Cao, "Consolidation/synthesis of materials by electric current activated/assisted sintering," Materials Science and Engineering: R: Reports, 63, 127 (2009)

13. R. Z. Valiev, R. K. Islamgaliev, I. V. J. Alexandrov, "Bulk nanostructured materials from severe plastic deformation," Prog. Mater. Sci., 45103 (2000).

14. M. Abdellaoui, E. Gaffet, "The physics of mechanical alloying in a planetary ball mill: Mathematical treatment," Acta Metallurgica et Materialia, 43, 1087 (1995)

15. E. Gaffet, F. Bernard, J.C. Niepce, F. Charlot, C. Gras, G.Le Caer, J.L. Guichard, P. Delcroix, A. Mocellin, O. Tillement, "Some recent developments in mechanical activation and mecanosynthesis," J. of Material Chemistry 9, 305 (1999)

16. C. K. H. Dharan and F. E Hauser, "Determination of stress-strain characteristics at very high strain rates," Exp. Mech 10, 370 (1970)

17. J. R. Klepaczko, Advanced experimental techniques in materials testing. In New experimental methods in material dynamics and impact (eds WKNowacki, JR Klepaczko), 223 (2001)

18. H. Couque, "The Use of the Direct Impact Hopkinson Pressure Bar Technique to Describe thermally Activated and Viscous Regimes of Metallic Materials," Philosophical Transactions of the Royal Society A, 372 (2014).

19. A. Le Bail, H. Duroy, J-L. Fourquet, "Ab-initio structure determination of LiSbWO6 by X-ray powder diffraction" Mat. Res. Bull., 23, 447 (1988).

20. O. Boytsov, E. Gaffet, F. Bernard, A. Ustinov, "Correlation between milling parameters and microstructure characteristics of nanocrystalline copper powder prepared via a high energy planetary ball mill," J. Alloys and Comp. 432, 103 (2007)

21. A. Bolsonella, F. Naimi, O. Heintz, T. Tricone, H. Couque, F. Bernard, "Influence of oxygen induced during high-energy ball milling process on the mechanical properties of sintered nickel by SPS," Journal of Alloys and Comp. 856, 157289 (2021) 